\title{
Hedonicity and Memory of Odors
}

\author{
Michel Cabanac (Corresponding author) \\ Department of Psychiatry \& Neurosciences \\ Faculty of Medicine Laval University \\ 1855 rue Commerciale, St-Jean Chrysostome, Québec G6Z 2L2, Canada
}

Tel: 1-418-839-5648Ｅ-mail: michel.cabanac@fmed.ulaval.ca

\author{
Marie-Claude Bonniot-Cabanac \\ Department of Psychiatry \& Neurosciences \\ Faculty of Medicine Laval University, Canada \\ E-mail: marie-claude.bonniot@fmed.ulaval.ca
}

$\begin{array}{ll}\text { Received: July 14, } 2011 & \text { Accepted: September 5, } 2011 \quad \text { Published: December 1, } 2011 \\ \text { doi:10.5539/ijps.v3n2p178 } & \text { URL: http://dx.doi.org/10.5539/ijps.v3n2p178 }\end{array}$

\begin{abstract}
The capacity of human observers to remember incidentally learned olfactory sensations as a function of their perceived pleasure/ displeasure was investigated. In the encoding phase of the experiment, the participants rated a sequence of 24 stimuli for (i) sensory intensity, and (ii) degree of pleasure or displeasure. They were then given two successive explicit memory tests, (i) free recall of the names of encountered odors, and (ii) yes/no recognition of the encountered odor stimuli. The results showed higher recall and recognition accuracy for the stimuli that had been rated higher in affective content at the time of study. These results support the hypothesis that hedonicity is a variable that influences the encoding and storage of events in memory.
\end{abstract}

Keywords: Odors, Memory, Pleasure, Displeasure, Free-recall, Recognition, Hedonicity

\section{Introduction}

“...the most basic function of consciousness is to present a particular physiological state of the organism as an affective response, so allowing the grounding of desires in the biology and pursuit of things that have biological utility" (Balleine \& Dickinson, 1998).

The memory for odors has been studied mostly from the point of view of odor recognition (Lawless \& Cain, 1975; Cain, 1988; Algom \& Cain, 1991; deWijk, Schab, \& Cain, 1995; Cain \& Potts, 1996). In the present work, the memory for odors is studied not from the point of view of recognition but from the hedonic dimension of the sensation aroused by the stimulus. Hedonicity is how we like or dislike a conscious experience. Hedonicity seems to be especially predominant with olfactory sensation (Royet, Zald, Versace, Coste, Lavenne, Koenig \& Gervais, 2000; Soussignan \& Schaal, 1996; Soussignan, Schaal \& Marlier, 1999). What will be studied, therefore, is the capacity to remember stimuli as a function of the amount of pleasure or displeasure aroused by the stimuli - in our case, odors. In the following pages, the term "pleasure/displeasure" will be considered as describing the hedonic dimension of consciousness (Cabanac, 1996).

The common "currency", that the brain will rely on when the incoming information is screened for memory-encoding and storage, is potential usefulness of the information for the organism. This usefulness is assessed on the basis of significant features of the stimuli carrying the information. The hedonic dimension of sensation has been proposed as the variable that estimates the usefulness of the presented stimuli (Cabanac, 1971). Usefulness in the case of sensation can be estimated from survival value with physiological criteria. Sensory pleasure thus would indicate useful stimuli that improve physiological functioning. Displeasure also has survival value since it would indicate noxious stimuli, and would therefore indicate negative usefulness. This role of pleasure and displeasure has been extended to behaviors other than those aiming at physiological purposes and has been proposed as the common currency that governs the trade offs among various conflicting motivations (Cabanac, 1992). It may therefore be hypothesized with Toates (1995), that pleasure/displeasure 
could also tag the usefulness and efficiency of all cognition and thinking, and serves as the motivational factor in all areas of cognition and thinking (Cabanac, 1996; Vuilleumier \& Huang, 2009). Cognition is understood here as implying an off-line modeling of the world.

This is a report of an experiment designed to assess this hypothesis in the case of memory. The "goodness" of a person's memory for a given event is known to depend on variables such as the nature of the event, the context within which it occurs, initial encoding and subsequent recoding operations performed on the input, and the extent to which retrieval cues match these operations (Tulving, 1983). It was shown also that slides arousing stronger emotions tended to be better remembered (Bradley, Greenwald, Petry \& Lang, 1992). The question addressed in the present experiment concerned the role of perceived or felt pleasure or displeasure evoked by the experienced stimulus events. The hypothesis was that the hedonic dimension of cognition, aroused by the events at encoding and stored in memory, plays an important role in remembering of the events. Pleasure/displeasure and emotion have long been recognized as dominant features in odorant stimulation (Brauchli, Ruegg, Etzweiler, \& Zeier, 1995; VernetMaury, Alaoui Ismaili, Dittmar, Delhomme, \& Chanel, 1999) and description (Schiffman, Robinson, \& Erickson, 1977) and memory (Herz \& Engen, 1996). EEG recordings demonstrate the deep influence of olfactory stimuli on the brain (Lorig, 1988; Lorig, Turner, Matia \& Warrenburg, 1995). "The most important function of the nose may be not in transmitting messages about the outside world, but in motivating the organism after the message has been received"(Engen, 1973); that function being already present in the newborn (Marlier, Schaal \&. Soussignan, 1997; Soussignan,,Schaal \& Marlier, 1999) and even intra utero (Marlier Marlier, Schaal \& Soussignan, 1998a, \& 1998b). Animal experiments have shown that odors followed by a reward were better remembered than non-rewarded odors (Lovelace \& Slotnick, 1995), which is a clue that memory privileges usefulness. It was demonstrated also that recollections evoked by odors are more emotional than those evoked verbally (Herz \& Cupchik, 1995), that verbal codes are not necessary for odor-associated memory (Herz, 2000) and finally that pleasant odors enhance approach behavior due to their hedonic dimension (Knasko, 1995). These findings suggest that the sensory stimulus in olfaction should provide a favorable paradigm to test the hypothesis that hedonicity is a potent factor for storing a piece of information into memory. Numerous studies have been devoted to the memory of odous (Engen \& Ross, 1973; Lawless \& Cain, 1975; Osaka, 1987; Algom \& Cain, 1991; Cain \& Potts, 1996), however, only Gordon, (1925) explored the relation between affect and memorability of odors. In that study no correlation was found between the memory value of odors and their hedonic value.

\section{Methods}

\subsection{Participants}

Twelve participants (6 males and 6 females) without any known respiratory or olfactory previous pathology gave informed consent and served individually as participants; all were non-smokers (Krebs, Petros \& Beckwith, 1994). As memory tends to decline over 50 yrs of age (Myerson Emery, White, \& Hale, 2003) participants were deliberately recruited younger and there was no age difference between sexes (mean age $24.7 \pm 0.8 \mathrm{yr}$ ). Although women frequently outperform men in olfactory sensitivity, especially at the time of ovulation, (Mair, Bouffard, Engen \& Morton, 1978) in memory tasks (LeMagnen, 1952; Koelega \& Kôster, 1974; Lehrner, 1993), and cortisol enhance memory in men only (Andreano \& Cahill, 2006), no sex difference was observed in the present experiment, and the data was therefore pooled.

Participants were exposed to a sequence of olfactory stimuli considered to be pleasant, unpleasant, or indifferent (or at least experienced as such by the experimenter). No mention was made of any upcoming memory test at the time of this encoding stage. Therefore, when they were subsequently tested for their recall and recognition of the presented stimuli, their memory was assessed for incidentally acquired information.

\subsection{Olfactory Stimuli}

1 imidazole crystals, 2 argame oil, 3 detergent, 4 coconut oil, 5 lemon flavor, 6 cheese, 7 rum, 8 orange flavor, 9 mushroom, 10 chocolate, 11 tobacco, 12 casein hydrolysate, 13 menthol, 14 clove, 15 naphthalene, 16 broth concentrate, 17 ground coffee, 18 cigarette buts, 19 thyme leaves, 20 tea leaves, 21 rotten meat, 22 lavender distillate, 23 ammonia, 24 geranium oil, 25 pure alcohol, 26 vinegar, 27 formalin, 28 dental cement, 29 rose distillate, 30 tar.

Most stimuli (at least 25 of them) were odous encountered in domestic life and, therefore, presumably familiar to the participants. After each 5-s stimulus the participant gave the name of the stimulus, possibly with the help of the experimenter in order to minimize the influence of labeling (Lehrner, 1993; Lorig, Turner \& Matia, 1995) and familiarity (Sulmont, Issanchou, \& Koster, 2002). The samples used as stimuli were stored in glass phials that were uncorked under the participant's nostrils during the stimulation. 


\subsection{Procedure}

The participants received the sequence of the 305 -s olfactory stimuli at the rate of one every $3 \mathrm{~min}$. All timing was measured from a stop-watch chronometer. Of these, the results obtained from the first three and the last three were discarded as they served the sole purpose of absorbing the primary and recency effects. Experimental interest was focused on the 24 items in the middle of the presentation sequence.

Three men and three women received the sequence of stimuli in ascending order, from $\# 1$ to $\# 30$, and to compensate for the influence of the sequence (Reed, 2000), three other men and women received the same sequence in descending order: from \#30 to \#1. After the presentation and naming of a given stimulus, the participant assigned it two kinds of ratings. First, the perceived intensity of the stimulus was to be rated on a linear magnitude estimation scale, from zero (no sensation) as anchor, to no limit as strongest possible sensation. Second, the perceived or felt pleasure or displeasure was rated on a magnitude estimation scale that extended from -d (extreme displeasure), through anchor at 0 (indifferent), to $+p$ (extreme pleasure). During the intervals between the presentations of individual stimuli participants were engaged in playing a computerized video game of their choice.

The retrieval phase of the experiment began 10 min after the presentation of the last stimulus. The participants spent this 10-min interval playing the video game. Before they were given two successive tests, participants were asked whether they had anticipated memory tests. All responded negatively. They were then given a free recall and yes/no recognition test, in this order.

For the free recall test, participants were allowed five minutes to write down, in any order, the names of the stimuli they could recall. They received credit for the recall of the 24 experimental stimuli; recall of the primacy (stimuli 1-3) and recency (stimuli 28-30) items was ignored. As what was of interest was the sensation memory rather than the stimulus name, approximate naming of a stimulus was accepted provided that there was no ambiguity (e.g., rotten, for rotten meat) and that debriefing showed accurate recognition.

Then, the sequence of 30 "old" stimuli was presented again to each participant together with six new odors that the participants had not encountered in the encoding sequence, distributed throughout the sequence. These six "new" test odors were: bleach, almond, phenol, maple, pine, and cypress.

The 36 test stimuli (6 ignored, 24 "old" and 6 "new") were presented one at a time, and the participant asked to (i) decide whether or not it had been presented in the first part of the experiment, and (ii) to assign a confidence rating to each decision, using a 3 -point scale: $3=$ certain, $2=$ rather sure, and $1=$ may be.

Odor adaptation was unlikely to take place in a 5-s exposure to each stimulus, nor cross adaption with 5-min intervals between stimuli.

\section{Results}

\subsection{Data Analysis}

The data analysis concerned the relation between stimulus hedonicity, on the one hand, and measures of recall and recognition, on the other. Pleasure/displeasure was considered as the motivational dimension of sensation and only the magnitude of the hedonic rating was taken into account, notwithstanding its sign. In 6 participants out of 12 the analysis of the crude ratings of pleasure/displeasure showed the expected influence of pleasure/displeasure on memory; however 2 of them, and 2 additional ones showed that intensity of sensation ranked above pleasure/displeasure in the correlation with memory. This is not surprising since there was a strong trend to correlation between ratings of intensity and affectivity: in 7 participants out of 12 the ratings of pleasure/displeasure correlated significantly $(\mathrm{P}<0.05)$ with the ratings of intensity. In 3 of the remaining 5 participants the hedonic ratings also tended to correlate with intensity ratings $(\mathrm{P}<0.1)$. In order to disentangle pleasure/displeasure of sensation from intensity, and assess the influence of pleasure/displeasure independently of intensity, each pleasure/displeasure rating assigned by a participant to a stimulus at encoding was divided by the corresponding intensity rating to yield a relative pleasure/displeasure index Q. Sensation with high pleasure/displeasure would produce a higher $\mathrm{Q}$, and intense sensation would produce a lower $\mathrm{Q}$. Thus the larger the resulting $\mathrm{Q}$, the more important the hedonic dimension of the sensation aroused by the stimulus, in relation to the intensity of the sensation. Each ratio Q was computed for each item. The data analysis took the form of comparing within-participant $Q$ ratios of remembered stimuli to those of not remembered stimuli (The results are also summarized in Table I).

\subsection{First Comparison}

The first comparison involved mean Q ratios for i) odor stimuli that were recalled in free recall, and ii) stimuli 
not recalled. For each participant the mean Qs of recalled and non-recalled stimuli were computed, then the overall mean of the group Qs was computed for recalled and non-recalled stimuli. Out of the 24 stimuli, the participants recalled (mean \pm s.e.) $12.3 \pm 0.9$ and did not recall $11.7 \pm 0.9$. The mean $\mathrm{Q}$ of the recalled stimuli was $1.14 \pm 0.19$, and the mean $\mathrm{Q}$ of the not recalled was $0.86 \pm 0.16$; the difference between the Qs of the recalled and not recalled was significant (Student's paired t, 3.27, $\mathrm{P}=0.008$ ). These data would show that stimuli evoking higher pleasure or displeasure were remembered more than those evoking less, whatever the intensity of sensation.

\subsection{Second Test}

In the second test, the new stimuli were included into the sequence of stimuli simply to detect whether a person declaring recognition of all stimuli would "cheat" when doing so. No participant gave sign of cheating and the results obtained with these new stimuli were discarded. The second comparison involved mean ratios for "old" stimuli that were correctly recognized as such and that were given the highest confidence rating ("yes" and 3) and "old" stimuli not recognized and rated certain ('no' and 3), or 'no' and 2 in case of participants who did not give any extreme confidence judgment. The results showed that the mean number of stimuli accurately recognized was $14.0 \pm 1.0$, while the number of stimuli inaccurately rejected was $2.1 \pm 0.3$. The mean ( \pm s.e.) Qs were $1.17 \pm 0.17$ for the acute recognitions, and $0.64 \pm 0.12$ for the inaccurate rejections; the difference between the Qs of the accurately recognized and inaccurately rejected was significant (Student's paired t, 2.75, $\mathrm{P}=0.021$ ). These recognition data confirm the recall data by showing that, independently from the intensity of the sensations aroused, affect-laden olfactory stimuli, those evoking more pleasure or displeasure, tended to be more memorable than hedonically indifferent stimuli.

\section{Discussion}

In past mood studies of memory, the participants' general hedonic state was modified from the olfactory stimulus itself (Ludvigson \& Rottman, 1989), or manipulated by the experimenters, either with drugs (Eich, 1980) or hypnosis (Bower, 1981), and the results aroused some controversy as they were sometimes not replicable, sometimes conflicting (Bower \& Mayer, 1989). The present work is different from previous studies on the influence of mood on memory because what was under study here was not the participant's background mood or state, but the pleasantness or unpleasantness of the stimulus itself. The important role of hedonicity in olfactory processing has been previously emphasized:

- Developmental processes seemingly act upon the hedonic integration of odors (Schaal, 1988).

- Higher electrodermal amplitude suggested that activation stemmed more from emotional or hedonic intensity than valence, and that unpleasant odors induced more arousal than pleasant odors (Royet, Plailly, Delon-Martin, Kareken, \& Segebarth, 2003). Neuro functional studies confirmed the predominant role of hedonicity in the processing of olfactory sensations (Gottfried, O'Doherty \& Dolan, 2003). They also showed that these hedonic processes activate broad areas of the brain (Barrett \& Wager, 2006).

- Self stimulation, presumably hedonically positive, enhances memory (Major \& White, 1978).

A well-designed brain, a product of a long evolution, would not store all incoming information to the same extent. To do so would rapidly result in the overloading of the brain's capacity to hold information. This is presumably why evolution has endowed the brain with a screening process that sorts out useful information from the less useful before storing it in long-term memory. Students of memory have identified a number of characteristics of stimuli that are correlated with their memorability (Tulving, 1983; Rubin \& Friendly, 1986), although it has not been always clear whether these characteristics have their effect on encoding or on retrieval. In the case of odors, "When people misidentify everyday odors, as they often do, their errors may conceivably lie in faulty perception or in faulty access to the names" and experiments showed that both were true (DeWijk, Schab \& Cain, 1995; Cain \& Potts, 1996). This is why approximate naming was accepted as valid answer in the second part of the present experiment. On the basis of positron emission tomography data that allow a separation between encoding and retrieval at the level of brain physiology, it has been suggested that novelty/familiarity of information is one criterion that the brain uses in such screening (Tulving \& Kroll, 1995; Nyberg, Cabeza \& Tulving, 1996). Indeed, during ontogeny, repeated exposure to odors result in higher sensitivity to human odors, and eventually to social discrimination (Schaal \& Porter, 1991).

Another dissociation might also take place with involvement of the right hemisphere in memory processes and the left hemisphere in emotional processes. (Royet \& Plailly, 2004). The amygdala seems to be especially involved in the successful encoding of positive and negative events (Kensinger \& Schacter, 2006a).

Ambient odors can facilitate verbal memory (Smith, Standing, \&. DeMan, 1982), independently from hedonicity. 
Yet, the results of the present experiment confirmed that stimuli with hedonic content were more likely to be remembered than stimuli without hedonic content (Schleidt, Neumann \& Morishita, 1988), independently of their previous familiarity. Such a conclusion does not confirm the absence of correlation between memory value of odors and their affective value reported previously (Gordon, 1925). Such a discrepancy is likely to be explained by the strong interference of the intensity of sensation with hedonicity. Only the use of the index R in the present report permitted to sort the influence of pleasure/displeasure from intensity. Kensinger et al. have shown the major influence of emotional components of consciousness on their storage in memory, especially with aging (Kensinger, Krendl \& Corkin, 2006; Kensinger, Piguet, Krendl \& Corkin, 2005; Kensinger \& Schacter, 2006b). Their results would be convergent with the present one if one considers that emotion is any conscious experience with intense hedonic dimension (Russell \& Barrett, 1999; Cabanac, 2002; Barrett, 2006a, 2006b).

Sensory pleasure/displeasure is the dimension of sensation that allows optimization of behavior, as seen from the physiologist point of view, that of immediate improvement of physiological function (Rossetti, Meckler \& Prablanc, 1994), and survival (Cabanac, 1971). The result of the present experiment, showing that pleasure/displeasure plays a role in the sorting of stimuli to be remembered is important not only for the understanding of memory encoding but also because it extends to information processing the claim that hedonic dimension of consciousness is the mental index of the usefulness and efficacy of thoughts and mental objects (Cabanac, Pouliot \& Everett, 1997). Such a role of pleasure/displeasure in memory would be congruent with the suggestion that odors are first categorized according to pleasantness, even involuntarily (Lebel \& Dubé, 1998; Bensafi, Rouby, Farget, Bertrand, Vigouroux \& Holley, 2002), and with a predominant role of hedonicity in the process of decision making (Cabanac, 1992; Balaskó, \& Cabanac 1998), in memory (Hayes, Morey, Petty, Seth, Smolski, McCarthy \& Labar, 2010) and as a motivation in general (Cabanac, 1996).

\section{Acknowledgements}

My thanks have to go to Endel Tulving for his generous help at each step of the present work, from conception, to manuscript writing.

This work was supported by the Conseil de la Recherche en Sciences Naturelles et en Génie (NSERC-Psychology), Canada, and by the Fondation de l'Université Laval.

\section{References}

Algom, D., \& Cain, W.S. (1991). Remembered odors and mental mixtures: tapping reservoirs of olfactory knowledge. Journal of experimental Psychology, 17, 1104-1119

Andreano, J. M., \& Cahill L. (2006). Glucocorticoid release and memory consolidation in men and women. Psychological Science, 17, 466-470. http://dx.doi.org/10.1111/j.1467-9280.2006.01729.x

Balaskó, M., \& Cabanac, M. (1998). Grammatical choice and affective experience in a second-language test. Neuropsychobiology, 37, 205-210. http://dx.doi.org/10.1159/000026504

Balleine B. \& Dickinson A. (1998) Consciousness: The interface between affect and cognition. In, Cornwell J. Consciousness and Human Identity. Oxford University Press.

Barrett, L. F. (2006a). Are emotions natural kinds? Perspectives on Psychological Science, 1, 28-58. http://dx.doi.org/10.1111/j.1745-6916.2006.00003.x

Barrett, L. F. (2006b). Solving the emotion paradox: Categorization and the experience of emotion. Personality and Social Psychology Review, 10, 20-46. http://dx.doi.org/10.1207/s15327957pspr1001_2

Barrett, L. F., \& Wager, T. D. (2006). The structure of emotion. Evidence from neuroimaging studies. Current Directions in Psychological Science, 15, 79-83. http://dx.doi.org/10.1111/j.0963-7214.2006.00411.x

Bensafi, M., Rouby, C., Farget, V., Bertrand, B., Vigouroux, M., \& Holley, A. (2002). Influence of affective and cognitive judgments on autonomic parameters during inhalation of pleasant and unpleasant odors in humans. Neuroscience Letters, 319, 162-166. http://dx.doi.org/10.1016/S0304-3940(01)02572-1

Bower, G.H. (1981). Mood and memory. American Psychologist, 36, 129-148. http://dx.doi.org/10.1037/0003-066X.36.2.129

Bower, G.H., \& Mayer, J.D. (1989). In search of mood-dependant retrieval. Journal of social Behavior and Personality, 4, 121-156

Bradley, M.M., Greenwald, M.K., Petry, M.C., \& Lang, P.J. (1992). Remembering pictures: pleasure and arousal in memory. Journal of experimental Psychology: Learning Memory and Cognition, 18, 379-390. 
http://dx.doi.org/10.1037/0278-7393.18.2.379

Brauchli, P., Ruegg, P.B.. Etzweiler, F., \& Zeier, H. (1995). Electrocortical and autonomic alteration by administration of pleasant and unpleasant odor. Chemical Senses, 20, 505-515. http://dx.doi.org/10.1093/chemse/20.5.505

Cabanac, M. (1971). Physiological role of pleasure. Science, 173, 1103-1107. http://dx.doi.org/10.1126/science.173.4002.1103

Cabanac, M. (1992). Pleasure: the common currency. Journal of theoretical Biology, 155, 173-200. http://dx.doi.org/10.1016/S0022-5193(05)80594-6

Cabanac, M. (1996). On the origin of consciousness, a postulate and its corrollary. Neuroscience biobehavioral Reviews, 20, 33-40. http://dx.doi.org/10.1016/0149-7634(95)00032-A

Cabanac, M. (2002). What is emotion? Behavioural Processes, 60, 69-84. http://dx.doi.org/10.1016/S0376-6357(02)00078-5

Cabanac, M., Pouliot, C., \& Everett, J. (1997). Pleasure as a sign of efficacy of mental activity. European Psychologist, 2, 226-234. http://dx.doi.org/10.1027/1016-9040.2.3.226

Cain, W.S. (1988). Olfaction. Stevens' handbook of experimental psychology. New York, John Wiley \& Sons. 2th, ed.

Cain, W.S., \& Potts, B.C. (1996). Switch and bait: probing the discriminative basis of odor identification via recognition memory. Chemical Senses, 21, 35-44. http://dx.doi.org/10.1093/chemse/21.1.35

DeWijk, R.A., Schab, F.R., \& Cain, W.S. (1995). Odor identification. Memory for Odors. Mahwah, New Jersey, Lawrence Earlbaum Associates, 21-37

Eich, E. (1980). The cue-dependant nature of state-dependant retrieval. Memory and Cognition, 8, 157-173. http://dx.doi.org/10.3758/BF03213419

Engen, T. (1973). The sense of smell. Annual Reviews of Psychology, 24, 187-206. http://dx.doi.org/10.1146/annurev.ps.24.020173.001155

Engen, T., \& Ross, B.M. (1973). Long-term memory of odors with and without verbal descriptors. Journal of experimental Psychology, 100, 221-227. http://dx.doi.org/10.1037/h0035492

Gordon, K. (1925). The recolection of pleasant and unpleasant odors. Journal of experimental Psychology, 8 , 225-239. http://dx.doi.org/10.1037/h0064822

Gottfried, J. A., O'Doherty, J., \& Dolan, J. (2003). Encoding oredictive reward value in human amygdala and orbitofrontal cortex. Science, 301, 1104-1107. http://dx.doi.org/10.1126/science.1087919

Hayes, J.P., Morey, R.A., Petty, C.M., Seth, S., Smolski, M.J., McCarthy, G., \& Labar, K.S. (2010). Staying cool when things get hot: emotion regulation modulates neural mechanisms of memory encoding. Frontiers in Human Neuroscience, 4, 10.3389/fnhum.2010.00230. http://dx.doi.org/10.3389/fnhum.2010.00230

Herz, R.S. (2000). Verbal coding in olfactory versus nonolfactory cognition. Memory and Cognition, 28, 957-964. http://dx.doi.org/10.3758/BF03209343

Herz, R.S., \& Cupchik, G.C. (1995). The emotional distinctiveness of odor-evoked memories. Chemical Senses, 20, 517-528. http://dx.doi.org/10.1093/chemse/20.5.517

Herz, R.S., \& Engen, T. (1996). Odor memory: Review and analysis. Psychonomic Bulletin and Review, 3, 300-313. http://dx.doi.org/10.3758/BF03210754

Kensinger, E. A., Krendl, A. C., \& Corkin, S. (2006). Memories of an emotional and a nonemotional event: effects of aging and delay interval. Experimental Aging Research, 32, 23-45. http://dx.doi.org/10.1080/01902140500325031

Kensinger, E. A., Piguet, O., Krendl, A. C., \& Corkin, S. (2005). Memory for contextual details: effects of emotion and aging. Psychology and Aging, 20, 241-250. http://dx.doi.org/10.1037/0882-7974.20.2.241

Kensinger, E. A., \& Schacter, D. L. (2006a). Amygdala activity is associated with the successful encoding of item, but not souce, information for positive and negative stimuli. The Journal of Neuroscience, 26, 2564-2570. http://dx.doi.org/10.1523/JNEUROSCI.5241-05.2006

Kensinger, E. A., \& Schacter, D. L. (2006b). When the Red Sox shocked the Yankees: Comparing negative and positive memories. Psychological Bulletin \& Review, 13, 757-763. http://dx.doi.org/10.3758/BF03193993 
Knasko, S.C. (1995). Pleasant odors and congruency: Effects on approach behavior. Chemical Senses, 20, 479-487. http://dx.doi.org/10.1093/chemse/20.5.479

Koelega, H.S., \& Kôster, F.P. (1974). Some experiments on sex differences in odor perception. Annals of the New York Academy of Sciences, 237, 234-246. http://dx.doi.org/10.1111/j.1749-6632.1974.tb49859.x

Krebs, S.J., T. V. Petros, T.V., \& Beckwith, B.E. (1994). Effect of smoking on memory for prose passages. Physiology and Behavior, 56, 723-727. http://dx.doi.org/10.1016/0031-9384(94)90233-X

Lawless, H.T., \& Cain, W.S. (1975). Recognition memory for odors. Chemical Senses and Flavors, 1, 331-337. http://dx.doi.org/10.1093/chemse/1.3.331

LeBel, J.L., \& Dubé, L. (1998). Understanding pleasures: source, experience, and remembrances. Advances in Consumers Research, 25, 176-180

Lehrner, J.P. (1993). Gender differences in long-term odor recognition memory: verbal versus sensory influences and the consistency of label use. Chemical Senses, 18, 17-26. http://dx.doi.org/10.1093/chemse/18.1.17

LeMagnen, J. (1952). Les phénomènes olfacto-sexuels chez l'homme. Archives des Sciences Physiologiques, 6, $125-160$

Lorig, T.S. (1988). Brain and odors: I. Alteration of human EEG by odor administration. Psychobiology, 16, 281-284

Lorig, T.S., Turner, J.M., Matia, D.C., \& Warrenburg, S. (1995). The contingent negative variation in an odor labeling paradigm. Psychophysiology, 32, 393-398. http://dx.doi.org/10.1111/j.1469-8986.1995.tb01222.x

Lovelace, C.T., \& Slotnick, B.M. (1995). Memory for brief, widely spaced odor presentations in the rat. Chemical Senses, 20, 183-190. http://dx.doi.org/10.1093/chemse/20.2.183

Ludvigson, H.W., \& Rottman, T.R. (1989). Effects of ambient odors of lavender and cloves on cognition, memory, affect and mood. Chemical Senses, 14, 525-536. http://dx.doi.org/10.1093/chemse/14.4.525

Mair, R.G., Bouffard, J.A., Engen, T., \& Morton, T.H. (1978). Olfactory sensitivity during the menstrual cycle. Sensory Processes, 2, 90-98

Major, R., \& White, N. (1978). Memory facilitation by self-stimulation reinforcement mediated by the nigro-neostriatal bundle. Physiology \& Behavior, 20, 723-733. http://dx.doi.org/10.1016/0031-9384(78)90298-6

Marlier, L., Schaal, B., \&. Soussignan, R. (1997). Orientation responses to biological odours in the human newborn. Initial pattern and postnatal plasticity. Comptes Rendus de l'Académie des Sciences, Paris, 320, 999-1005

Marlier, L., Schaal, B., \&. Soussignan, R. (1998a). Bottle-fed neonates prefere an odor experienced in utero to an odoir experienced postnatally in the feeding context. Developmental Psychobiology, 33, 133-145. http://dx.doi.org/10.1002/(SICI)1098-2302(199809)33:2<133::AID-DEV4>3.0.CO;2-K

Marlier, L., Schaal, B., \&. Soussignan, R. (1998b). Neonatal responsiveness to the odor of amniotic and lacteal fluids: A test of perinatal chemosensory continuity. Child Development, 69, 611-623

Myerson, J., Emery, L., White, D. A., \& Hale, S. (2003). Effects of age, domain, and processing demands on memory span: Evidence for differential decline. Aging, Neuropsychology, and Cognition, 19, 20-27

Nyberg, L., Cabeza, R., \& Tulving, E. (1996). PET studies of encoding and retrieval: the HERA model. Psychonomic Bulletin and Review, 3, 135-148. http://dx.doi.org/10.3758/BF03212412

Osaka, N. (1987). Memory psychophysics for pyridine smell scale. Bulletin of the Psychonomic Society, 25, 56-57

Reed, P. (2000). Serial position effects in recognition memory for odors. Journal of experimental Psychology-Learning memory and Cognition, 26, 411-422. http://dx.doi.org/10.1037/0278-7393.26.2.411

Rossetti, Y., Meckler, C., \& Prablanc, C. (1994). Is there an optimal arm posture? Deterioration of finger localization precision and comfort sensation in extreme arm-joint postures. Experimental Brain Research, 99, 131-136. http://dx.doi.org/10.1007/BF00241417

Royet, J.-P., \& Plailly, J. (2004). Lateralization of olfactory processes. Chemical Senses, 29, 731-745. http://dx.doi.org/10.1093/chemse/bjh067

Royet, J.-P., Plailly, J., Delon-Martin, C., Kareken, D. A., \& Segebarth, C. (2003). fMRI of emotional responses to odors: influence of hedonic valence and judgment, handedness, and gender. NeuroImage, 20, 713-728. 
http://dx.doi.org/10.1016/S1053-8119(03)00388-4

Royet, J.-P., Zald, D., Versace, R., Coste, N., Lavenne, F., Koenig, O., \& Gervais, R. (2000). Emotional responses to pleasant and unpleasant olfactory, visual, and auditory stimuli: a positron emission tomography study. The Journal of Neuroscience, 20, 7752-7759

Rubin, D.C., \& Friendly, M. (1986). Predicting which words get recalled: measures of free recall, availability, goodness, and pronounceability for 925 nouns. Memory and Cognition, 14, 79-94. http://dx.doi.org/10.3758/BF03209231

Russell, J. A., \& Barrett, L. F. (1999). Core affect, prototypical emotional episodes, and other things called Emotion: Dissecting the elephant. Journal of Personality and Social Psychology, 76, 805-819. http://dx.doi.org/10.1037/0022-3514.76.5.805

Schaal, B. (1988). Olfaction in infants and children: developmental and functional perspectives. Chemical Senses, 13, 145-190. http://dx.doi.org/10.1093/chemse/13.2.145

Schaal, B., Porter, R.H. (1991). "Microsmatic Humans" revisited: The generation and perception of chemical signals. Advances in the Study of Behavior, 20, 135-199. http://dx.doi.org/10.1016/S0065-3454(08)60321-6

Schiffman, S., Robinson, D.E., \& Erickson, R. (1977). Multidimensional scaling of odorants: examination of psychological and physiological dimensions. Chemical Senses and Flavor, 2, 367-379. http://dx.doi.org/10.1093/chemse/2.3.375

Schleidt, M., Neumann, P., \& Morishita, H. (1988). Pleasure and disgust: memories and associations of pleasant and unpleasant odours in Germany and Japan. Chemical Senses, 13, 279-293. http://dx.doi.org/10.1093/chemse/13.2.279

Smith, D.G., L., \& DeMan, A. (1992). Verbal memory elicited by ambient odor. Perceptual and Motor Skills, 74, 339-343

Soussignan, R., \& Schaal, B. (1999). Children. Facial responsiveness to odors: Influences of hedonic valence of odors, gender, age, and social présence. Developmental Psychobiology, 32, 3-14. http://dx.doi.org/10.1002/(SICI)1098-2302(199907)35:1<3::AID-DEV2>3.0.CO;2-F

Soussignan, R., Schaal, B., \& Marlier, L. (1999). Olfactory alliesthesia in human neonates: Prandial state and stimulus familiarity modulate facial and autonomic responses to milk odors. Developmental Psychobiology, 35, 3-14. http://dx.doi.org/10.1002/(SICI)1098-2302(199907)35:1<3::AID-DEV2>3.0.CO;2-F

Sulmont, C., Issanchou, S., \& Koster, E. P. (2002). Selection of odorants for memory tests on the basis of familiarity, perceived complexity, pleasantness, similarity and identification. Chemical Senses, 27, 307-317. http://dx.doi.org/10.1093/chemse/27.4.307

Toates, F. (1995). Cognition and evolution - An organization of action perspective. Behavioural Processes, 35, 1-3. http://dx.doi.org/10.1016/0376-6357(95)00058-5

Tulving, E. (1983). Elements of Episodic Memory. Oxford, Oxford University Press.

Tulving, E., \& Kroll, N. (1995). Novelty assessment in the brain and long-term memory encoding. Psychonomic Bulletin and Review, 2, 387-390. http://dx.doi.org/10.3758/BF03210977

Vernet Maury E., Alaoui Ismaili, O., Dittmar, A., Delhomme, G., \& Chanel, J. (1999). Basic emotions induced by odorants: a new approach based on autonomic pattern results. Journal of the Autonomic Nervous System, 75, 176-183. http://dx.doi.org/10.1016/S0165-1838(98)00168-4

Vuilleumier, P., \& Huang, Y.M. (2009). Emotional attention. Uncovering the mechanisms of affective biases in $\begin{array}{llllll}\text { perception. Current Directions in Psychological Science, } & 18, & 148-152 .\end{array}$ http://dx.doi.org/10.1111/j.1467-8721.2009.01626.x

Table 1. Mean Q index in results from the two protocols followed: free recall and recognition

\begin{tabular}{|l|l|l|}
\hline Free recall & & \\
$12.3+0.9$ stimuli recalled & $\mathrm{Q}=1.14 \pm 0.19$ & $\mathrm{P}=0.008$ \\
$11.7+0.9$ stimuli not recalled & $\mathrm{Q}=0.86 \pm 0.16$ & \\
\hline Recognition & & \\
$14.0+1.0$ stimuli accurately recognized & $\mathrm{Q}=1.17 \pm 0.19$ & $\mathrm{Q}=0.021$ \\
$2.1+0.3$ stimuli inaccurately rejected & $\mathrm{Q}=0.64 \pm 0.12$ & $\mathrm{P}=0.02$ \\
\hline
\end{tabular}

